\title{
Persepsi Masyarakat Pengguna Jaminan Kesehatan Nasional (JKN) tentang Pelayanan Kesehatan Masyarakat di RSUD Dr. H. Slamet Martodirdjo Pamekasan Madura
}

\author{
Dwi Marita Fitriana A.S \& Imamul Hakim \\ Program Studi Ekonomi Syariah, Fakultas Agama Islam, \\ Universitas Muhammadiyah Malang \\ E-mail: marita.salim12@gmail.com
}

\begin{abstract}
This study aims to determine the public perception of health services that use the program of National Health Insurance in Dr. H. Slamet Martodirdjo Pamekasan Madura as well as the existence of BPJS Health itself. This type of research is descriptive quantitative. Methods of data collection in this study is to use questionnaires (questionnaires) and interviews. The sample in this research is obtained by purposive sampling method. Based on the existing criteria, obtained 168 respondents. Data analysis method is done by using likert scale, with data scoring analysis technique. Based on the results of data analysis from the existing sub-dimensions, some sub dimensions responded positively by the community, some sub dimensions responded to doubt / neutral such as the availability of drugs for patients BPJS, BPJS patient acceptance procedures, and sub dimensions of hospitality, courtesy. The best community response is in the Assurance dimension associated with the availability of a specialist physician with a score of 707 in the agreed category. Neutral response with the highest score of 570 is in the sub-dimension of the doctor trying to calm the patient's anxiety about the illness suffered. In addition there is also a negative response that is in the sub Empathy (concern) related nurses spend a special time to communicate with patients score 404 in the category disagree. In addition to the sub dimensions of access (acess) related service personnel do not discriminate the patient's economy responded negatively with a score of 398 in the category disagree.
\end{abstract}

Keywords: Public Perception, BPJS, Health Services. 


\section{Pendahuluan}

Pengetahuan akan asuransi itu sendiri secara mendalam masyarakat belum mengenal dan mengetahuinya. ${ }^{1}$ Misalkan saja pada kelompok masyarakat miskin, pengetahuan tentang asuransi sangatlah minim salah satu penyebab minimnya pengetahuan tentang asuransi yaitu kurangnya sosialisasi tentang pentingnya asuransi untuk kalangan bawah dan mahalnya biaya kesehatan yang layak. Hal tersebut menjadi faktor penyebab tidak setaranya derajat kesehatan yang dimiliki antara orang miskin dan orang kaya. mahalnya fasilitas kesehatan yang berada di rumah sakit umum yang menyebabkan kesempatan yang tidak sama bagi setiap orang untuk menikmati hak-haknya di bidang kesehatan. Rumah Sakit merupakan sarana pelayanan kesehatan yang bertujuan menyelenggarakan pelayanan kesehatan perorangan secara paripurna, lebih difokuskan pada upaya promosi kesehatan dan pencegahan (preventif) dengan tidak mengabaikan upaya kuratifrehabilitatif yang menyediakan pelayanan rawat inap, rawat jalan dan gawat darurat. Selain itu, pelayanan kesehatan di rumah sakit bukan hanya kepada individu (pasien), tetapi juga keluarga dan masyarakat, sehingga pelayanan kesehatan yang dilakukan merupakan pelayanan kesehatan yang paripurna (komprehensif dan holistik). ${ }^{2}$

BPJS (Badan Penyelenggara Jaminan Sosial) merupakan salah satu dari sekian banyak jenis asuransi di Indonesia. BPJS yaitu sebuah Badan Hukum Publik yang berperan untuk menyelenggarakan Jaminan Pemeliharaan Kesehatan bagi seluruh warga negara Indonesia yang diresmikan pada 31 Desember 2013 atau di dalam BPJS sendiri disebut program JKN-KIS (Jaminan Kesehatan Nasional-Kartu Indonesia Sehat). ${ }^{3}$ Meskipun BPJS Kesehatan ini menjadi trend di masa sekarang, tak banyak dari kalangan masyarakat mengeluhkan pelayanan dengan menggunakan BPJS. Seperti kasus ketika Komisi IV Dewan Perwakilan Rakyat Daerah (DPRD) Pamekasan, Madura, Jawa Timur, melakukan inspeksi mendadak (sidak) ke Rumah Sakit Umum Daerah (RSUD) dr. H. Slamet Martodirdjo, Pamekasan, Selasa, 7 Maret 2017. Sidak tersebut dilatarbelakangi banyak pengaduan dari masyarakat yang mengeluhkan pelayanan di rumah sakit pelat merah tersebut. Utamanya, pada pasien pemegang kartu BPJS (Badan Penyelenggara Jaminan Sosial). Anggota DPRD langsung memeriksa keberadaan dokter, sebab salah satu keluhan yang masuk ke DPRD lambat pelayanan karena dokternya kerap tidak ada. "Keluhan yang kami terima, pasien jalur BPJS terkesan dianaktirikan, karena lama menunggu hingga terjadi antrean panjang.

1 Novita Riyanti K.D, PENGETAHUAN MASYARAKAT TENTANG PROGRAM JAMINAN KESEHATAN NASIONAL (JKN) di Desa Wiyono Kecamatan Gedong Tataan Kabupaten Pesawaran, ( Lampung: Universitas Lampung, 2017), 12-13

${ }^{2}$ Ahmad Sjafii, Undang-Undang Republik Indonesia no. 44 tahun 2009 tentang Rumah Sakit, (Jakarta, Departemen Kesehatan Republik Indonesia, 2009), 1

3 Sekilas Tentang BPJS, diakses pada tanggal 21 Maret 2017, pukul 13:03 WIB dari http://www.bpjskesehatan.link/2015/03/apa-itu-bpjs-kesehatan.html 
Makanya, kami melakukan sidak terkait pelayanan di rumah sakit ini," kata Sahur. $^{4}$

Menurut data yang diperoleh dari Kantor Cabang BPJS Kesehatan Kabupaten Pamekasan, tercatat kurang lebih 612.770 total jumlah peserta yang menjadi anggota BPJS Kesehatan sedangkan jumlah penduduk di kabupaten pamekasan tercatat kurang lebih 869.636 orang. Dari data di bawah ini dapat ditarik kesimpulan bahwasanya sekitar 256.866 dari jumlah penduduk belum mendaftarkan diri menjadi peserta BPJS Kesehatan.

Tabel 1.1: Jumlah Peserta JKN-KIS di Wilayah Pamekasan

\begin{tabular}{|c|c|c|c|c|c|c|c|}
\hline \multirow{2}{*}{ No } & Wilayah & $\begin{array}{c}\text { Jumlah } \\
\text { Penduduk }\end{array}$ & $\begin{array}{c}\text { Penerima } \\
\text { Bantuan } \\
\text { Iuran }\end{array}$ & $\begin{array}{c}\text { Pekerja } \\
\text { Penerima } \\
\text { Upah }\end{array}$ & $\begin{array}{c}\text { Pekerja } \\
\text { Bukan } \\
\text { Penerima } \\
\text { Upah } \\
\text { (PBPU) }\end{array}$ & $\begin{array}{c}\text { Penerima } \\
\text { Bantuan } \\
\text { Iuran } \\
\text { Daerah } \\
\text { (PBID) }\end{array}$ & $\begin{array}{c}\text { Jumlah } \\
\text { Peserta } \\
\text { KISN- } \\
1\end{array}$ \\
\hline $\begin{array}{c}\text { Kab. } \\
\text { Pamekasan }\end{array}$ & 869.636 & 494.271 & 51.357 & 26.349 & 28.028 & 612.770 \\
\hline
\end{tabular}

Sumber: Data BPJS Kesehatan Pamekasan 2017

Dengan demikian, perlu dilakukan kajian secara mendalam terkait bagaimana persepsi masyarakat tentang pelayanan kesehatan masyarakat yang menggunakan program jaminan kesehatan nasional di RSUD Dr. H. Slamet Martodirdjo Pamekasan Madura?.

\section{Pelayanan Kesehatan, Kualitas Pelayanan}

Penelitian ini adalah deskriptif kuantitatif. Teknik pengumpulan data dalam penelitian ini menggunakan angket (kuesioner) dan wawancara secara langsung. Dalam penelitian ini populasinya adalah rata-rata jumlah seluruh pasien rawat inap yang terdaftar dalam program JKN-KIS (Jaminan Kesehatan Nasional- Kartu Indonesia Sehat) dari bulan januari-april 2017 sejumlah 861

\footnotetext{
${ }^{4}$ Ali Syahroni, Makin Banyak Pengaduan tentang Pelayanan RSUD Dr.H.Slamet Martodirdjo, diakses pada tanggal 15 Oktober 2017 pukul 18:35 WIB dari http://www.saidabdullah.info/makinbanyak-pengaduan-tentang-pelayanan-rsud-dr-h-slamet-martodirdjo/
} 
Tabel 3.1: Kunjungan Pasien BPJS di RSUD Dr.H. Slamet Martodirdjo Pamekasan 2017

\begin{tabular}{|c|c|c|}
\hline Bulan & Rawat Jalan & Rawat Inap \\
\hline Januari & 4808 & 927 \\
\hline Februari & 4377 & 797 \\
\hline Maret & 4969 & 862 \\
\hline April & 5080 & 857 \\
\hline Total & $\mathbf{1 9 . 2 3 4}$ & $\mathbf{3 . 4 4 3}$ \\
\hline \multicolumn{2}{|c|}{$\overline{\mathrm{x}}=\frac{\text { Total Pasien Rawat Inap }}{\text { banyaknya bulan }}=\frac{3.443}{4}=\mathbf{8 6 1}$} \\
\hline
\end{tabular}

Sumber: Kantor BPJS Kesehatan Pamekasan

Teknik sampling pada penelitian ini menggunakan teknik Nonprobability sampling dengan metode purposive sampling. Sampel yang di ambil yakni 206 dengan taraf kesalahan $10 \% .{ }^{5}$ Sedangkan sumber data yang digunakan adalah data primer (wawancara dan penyebaran angket) dan data sekunder (literatur, artikel, jurnal serta situs di internet yang berkenaan dengan penelitian). Metode yang digunakan dalam penelitian ini berupa pernyataan dalam kuisioner yang diukur dengan menggunakan model skala likert yang berhubungan dengan pernyataan tentang sikap seseorang terhadap sesuatu. ${ }^{6}$ Adapun Teknik analisis data dari penelitian ini dengan menggunakan sistem skoring.

Uji instrument yang digunakan adalah uji validitas dan reliabilitas, Validitas merupakan suatu alat pengukur untuk mengukur apa yang diukur guna menunjukkan tingkat kesahihahn suatu instrumen dengan menggunakan rumus Pearson Product Moment.. ${ }^{7}$ Reliabilitas adalah istilah yang digunakan untuk menunjukkan sejauh mana suatu hasil pengukuran relatif konsisten apabila pengukuran tersebut dipakai dua kali atau lebih dengan menggunakan rumus cronbach alpha. ${ }^{8}$

\subsection{Klasifikasi Responden}

Berdasarkan penyebaran angket kepada responden sebanyak 206, terdapat 168 responden yang sesuai dengan kriteria peneliti. Dari 168 responden diolah menjadi tabel serta uraian dari masing-masing variabel. Dalam penelitian yang berjudul persepsi masyarakat tentang pelayanan masyarakat yang menggunakan BPJS Kesehatan di Rumah Sakit Umum Daerah Dr. H. Slamet Martodirdjo

\footnotetext{
${ }^{5}$ Stephen Issac\& W.B Michael, Handbook in research and evaluation, (SanDiego, 1984), 146

6 Sugiyono, Metode Penelitian Administrasi Dilengkapi dengan Metode R\&D, (Bandung, 2001), 107

${ }^{7}$ Suharsimi Arikunto, Prosedur Penelitian Suatu Pendekatan Praktek, (Jakarta, 2002), 141.

${ }^{8}$ Ibid,Suharsimi Arikunto, Prosedur Penelitian Suatu Pendekatan Praktek, 140
} 
Pamekasan Madura banyak masyarakat yang merespon positif terhadap pelayanannya dan adapula yang merespon negatif. Hal ini dapat dilihat dari tiaptiap dimensi yang ada dan diberikan oleh pihak rumah sakit sebagai mitra kerja dari BPJS Kesehatan Pamekasan kepada masyarakat. Diketahui bahwa responden paling dominan berdasarkan jenis kelamin yakni perempuan sebanyak 88 responden dan 80 responden laki-laki. Berdasarkan pendidikan terakhir yakni dengan pendidikan terakhir SMA/SLTA sebanyak 70 orang, disusul S1 sebanyak 40 orang. Dominan yang menggunakan BPJS Kesehatan di RSUD Dr. H. Slamet Martodirdjo Pamekasan yakni dari buruh tani sebanyak 35 orang, disusul wiraswasta 27 orang, guru 24 orang, Ibu rumah tangga 21 orang dan pengangguran 18 orang.

2.2. Hasil uji istrumen validitas dan reliabilitas

Berdasarkan hasil analisis diatas dapat diketahui bahwa r-hitung > r-tabel, sehingga dapat disimpulkan bahwa semua item pertanyaan/pernyataan adalah valid.

Tabel 2.1: Hasil Uji Validitas

\begin{tabular}{|c|c|c|c|}
\hline $\begin{array}{c}\text { No } \\
\text { Item }\end{array}$ & $\boldsymbol{r}_{\boldsymbol{x y}}$ & $\begin{array}{c}\text { r-tabel } \\
\mathbf{5 \% ( 3 0 )}\end{array}$ & Ket \\
\hline 1 & 0,452 & 0,361 & Valid \\
\hline 2 & 0,376 & 0,361 & Valid \\
\hline 3 & 0,467 & 0,361 & Valid \\
\hline 4 & 0,427 & 0,361 & Valid \\
\hline 5 & 0,399 & 0,361 & Valid \\
\hline 6 & 0,499 & 0,361 & Valid \\
\hline 7 & 0,565 & 0,361 & Valid \\
\hline 8 & 0,773 & 0,361 & Valid \\
\hline 9 & 0,381 & 0,361 & Valid \\
\hline 10 & 0,617 & 0,361 & Valid \\
\hline 11 & 0,662 & 0,361 & Valid \\
\hline 12 & 0,382 & 0,361 & Valid \\
\hline 13 & 0,405 & 0,361 & Valid \\
\hline 14 & 0,389 & 0,361 & Valid \\
\hline 15 & 0,572 & 0,361 & Valid \\
\hline 16 & 0,376 & 0,361 & Valid \\
\hline
\end{tabular}

\begin{tabular}{|l|l|l|l|}
\hline 17 & 0,405 & 0,361 & Valid \\
\hline 18 & 0,374 & 0,361 & Valid \\
\hline 19 & 0,366 & 0,361 & Valid \\
\hline 20 & 0,377 & 0,361 & Valid \\
\hline 21 & 0,409 & 0,361 & Valid \\
\hline 22 & 0,572 & 0,361 & Valid \\
\hline 23 & 0,367 & 0,361 & Valid \\
\hline 24 & 0,403 & 0,361 & Valid \\
\hline 25 & 0,694 & 0,361 & Valid \\
\hline 26 & 0,397 & 0,361 & Valid \\
\hline 27 & 0,412 & 0,361 & Valid \\
\hline 28 & 0,612 & 0,361 & Valid \\
\hline 29 & 0,367 & 0,361 & Valid \\
\hline 30 & 0,393 & 0,361 & Valid \\
\hline 31 & 0,411 & 0,361 & Valid \\
\hline 32 & 0,367 & 0,361 & Valid \\
\hline 33 & 0,473 & 0,361 & Valid \\
\hline
\end{tabular}

Sumber: Hasil pengolahan data kuisioner sementara 2017 
Tabel 2.2: Uji Reliabilitas

\begin{tabular}{|c|c|c|c|c|c|c|c|}
\hline \multirow{2}{*}{$\begin{array}{c}\text { No } \\
\text { item }\end{array}$} & \multirow{2}{*}{$\begin{array}{l}\text { Cronba } \\
\text { ch's } \\
\text { Alpha if } \\
\text { item } \\
\text { deleted }\end{array}$} & \multirow{2}{*}{$\begin{array}{c}\text { Cronba } \\
\text { ch } \\
\text { Alpha }\end{array}$} & \multirow[t]{2}{*}{ Ket. } & 17 & 0,956 & 0,60 & Reliabel \\
\hline & & & & 18 & 0,956 & 0,60 & Reliabel \\
\hline 1 & 0,958 & 0,60 & Reliabel & 19 & 0,958 & 0,60 & Reliabel \\
\hline 2 & 0,958 & 0,60 & Reliabel & 20 & 0,957 & 0,60 & Reliabel \\
\hline 3 & 0,958 & 0,60 & Reliabel & 21 & 0,957 & 0,60 & Reliabel \\
\hline 4 & 0,958 & 0,60 & Reliabel & 22 & 0,955 & 0,60 & Reliabel \\
\hline 5 & 0,959 & 0,60 & Reliabel & 23 & 0,956 & 0,60 & Reliabel \\
\hline 6 & 0,959 & 0,60 & Reliabel & 24 & 0,958 & 0,60 & Reliabel \\
\hline 7 & 0,959 & 0,60 & Reliabel & 25 & 0,957 & 0,60 & Reliabel \\
\hline 8 & 0,958 & 0,60 & Reliabel & 26 & 0,956 & 0,60 & Reliabel \\
\hline 9 & 0,956 & 0,60 & Reliabel & 27 & 0,956 & 0,60 & Reliabel \\
\hline 10 & 0,959 & 0,60 & Reliabel & 28 & 0,955 & 0,60 & Reliabel \\
\hline 11 & 0,957 & 0,60 & Reliabel & 29 & 0,956 & 0,60 & Reliabel \\
\hline 12 & 0,956 & 0,60 & Reliabel & 30 & 0,957 & 0,60 & Reliabel \\
\hline 13 & 0,955 & 0,60 & Reliabel & 31 & 0,959 & 0,60 & Reliabel \\
\hline 14 & 0,955 & 0,60 & Reliabel & 32 & 0,959 & 0,60 & Reliabel \\
\hline 15 & 0,955 & 0,60 & Reliabel & 33 & 0,958 & 0,60 & Reliabel \\
\hline
\end{tabular}



Berdasarkan hasil di atas Cronbach Alpha > 0,60, maka seluruh item pertanyaan atau pernyataan dikatakan reliabel. Berikut ini merupakan ringkasan dari hasil penelitian yang dilakukan di rumah sakit Dr.H.Slamet Martodirdjo Pamekasan.

\section{Tabel 2.3: Dimensi Pelayanan}

\begin{tabular}{|c|c|c|c|c|c|c|}
\hline Bukti Nyata & Kehandalan & $\begin{array}{c}\text { Daya } \\
\text { Tanggap }\end{array}$ & Jaminan & Kepedulian & Keramahan & Akses \\
\hline 1. $S-558$ & 1. $N-498$ & 1. $N-467$ & 1. S - 707 & 1. $N-570$ & 1. $N-474$ & 1. TS - 398 \\
\hline & 2. $N-458$ & 2. S - 604 & & 2. $N-488$ & 2. $N-540$ & $25-647$ \\
\hline 3. S - 676 & 3. S - 609 & 3. S - 658 & 3. S- 589 & 3. S - 577 & 3. $N-493$ & 3. $5-684$ \\
\hline 4. S - 660 & 4. $N-650$ & 4. S - 646 & 4. $N-565$ & 4. $\mathrm{N}-494$ & & 4.540 \\
\hline 5. N- 501 & 5. N - 541 & 5. $N-483$ & 5. S - 639 & 5. TS - 404 & & $4.3-040$ \\
\hline
\end{tabular}

Sumber: Hasil penelitian pada pasien 2017

Berdasarkan tabel 4.10 dapat dilihat bahwasanya skor tertinggi berada pada dimensi pelayanan assurance (jaminan), yakni 707 dengan kategori setuju terkait tersedianya dokter spesialis. Hal ini sesuai dengan yang tertera pada brosur rumah sakit Dr.H. Slamet Martodirdjo Pamekasan. Dalam brosur tersebut tertera dengan jelas dokter-dokter spesialis penyakit. Adapun skor menengah berada pada dimensi pelayanan empathy (kepedulian), yakni 570 dengan kategori netral terkait dokter berusaha menenangkan rasa cemas pasien terhadap penyakit yang diderita, hal ini berdasarkan observasi peneliti dan keluhan dari pasien dan keluarga pasien bahwasanya ada beberapa petugas pelayanan terutama dokter ketika dibutuhkan tidak segera datang. Hal ini terjadi karena pasien yang datang ke rumah sakit tersebut juga banyak. Skor terendah yakni 398 dengan kategori tidak setuju ada pada dimensi access (akses) terkait petugas pelayanan yang membeda-bedakan ekonomi pasien. Hal ini sesuai dengan keluhan dan pengalaman pasien dan keluarga pasien yang pernah rawat inap di rumah sakit Dr.H.Slamet Martodirdjo Pamekasan.

\section{Kesimpulan}

Berdasarkan penelitian yang telah dilakukan, dari sub-sub dimensi yang ada, beberapa sub dimensi direspon positif oleh masyarakat, sebagian sub dimensi direspon ragu-ragu/netral diantaranya yaitu ketersediaan obat bagi pasien BPJS, prosedur penerimaan pasien BPJS, dan sub dimensi keramahan, kesopanan. Respon paling baik masyarakat ada pada dimensi Assurance (Jaminan) terkait dengan tersedianya dokter spesialis dengan skor 707 dalam kategori setuju. 
Respon netral dengan skor tertinggi 570 ada pada sub dimensi dokter berusaha menenangkan rasa cemas pasien terhadap penyakit yang diderita. Selain itu ada pula yang di respon negatif yakni pada sub Empathy (kepedulian) terkait perawat meluangkan waktu khusus untuk berkomunikasi dengan pasien skor 404 dalam kategori tidak setuju. Selain itu pada sub dimensi Acess (akses) terkait petugas pelayanan tidak membeda-bedakan ekonomi pasien direspon negatif dengan skor 398 dalam kategori tidak setuju.

Bagi pihak rumah sakit, pelayanan terkait keramahan, kesopanan harap dijadikan bahan evaluasi karena motto pelayanan rumah sakit sendiri harap dijadikan bahan evaluasi karena motto pelayanan rumah sakit sendiri yakni $3 \mathrm{~S}$ (SALAM, SAPA, SENYUM), pada kenyataannya banyak pasien pengguna Jaminan Kesehatan Nasional BPJS masih ragu-ragu dalam hal tersebut. Adapun waktu luang perawat untuk berkomunikasi dengan pasien lebih di tingkatkan sehingga tidak ada respon negatif terkait hal tersebut dan keluhan pasien dapat tersampaikan. Disamping itu, masih banyak yang menjawab tidak setuju pada sub dimensi tidak membeda-bedakan ekonomi pasien dan harap hal ini menjadi evaluasi bahwasanya dalam hal pelayanan tidak pandang bulu sehingga pelayanan merata dan masyarakat dapat merespon positif. Bagi Instansi BPJS sendiri, yakni mengevaluasi setiap mitra kerjanya, dan fasilitas kesehaan yang dijanjikan, karena bukan tidak mungkin dari hal tersebut bisa memberikan dampak negatif terhadap BPJS sendiri mengingat data yang sebelumnya tercatat sekitar 256.866 penduduk belum mendaftarkan diri menjadi peserta Jaminan Kesehatan Nasional. Selain itu diharapakan nantinya ada program dari BPJS yang berprinsip syariah, mengingat juga bahwa mayoritas penduduk pamekasan beragama Islam, tentunya akan sangat mudah menarik minat masyarakat setempat dan tentu operasionalnya benar-benar dijalankan sesuai dengan prinsip syariah.

\section{Daftar Pustaka}

Arikunto, Suharsimi. 2009. Dasar-dasar Evaluasi Pendidikan. Jakarta: Aneka Cipta

Basuki, Sulistyo. 2006. Metode Penelitian. Jakarta: Wedatama Widya Sastra.

Bin Nashir as-Sa'di, Syaikh Abdurrahman. 2006. Taisir al-Karimir Rahman fi Tafsir Kalam al-Manna. Beirut. Mu'asasah ar-Risalah.

Feldman, Robert S. 2012. Pengantar Psikologi. Jakarta: Salemba Humanika.

Fitri Permata Sari. 2015. Persepsi Masyarakat Pengguna Badan Penyelenggara Jaminan Sosial (BPJS) Kesehatan Mandiri Dalam Pelayanan RSUD Lubuk Basung Kabupaten Agam. Skripsi Jurusan Sosiologi, Riau Pekanbaru.

Fuzna Elsa Ulinuha. Kepuasan Pasien BPJS (Badan Penyelenggara Jaminan Sosial) Terhadap Pelayanan di Unit Rawat Jalan (URJ) Rumah Sakit 
Internet:

Ayut Dewantari Putri, Pengaruh Kualitas Pelayanan Terhadap Kepuasan Pasien Peserta BPJS di Rumah Sakit Tingkat II Udayana Denpasar, diakses pada tanggal 15 Mei 2017 pukul 10.32 WIB dari http://ojs.unud.ac.id/index.php/citizen/article/view/19312/12792

Erni Susanti. Hak dan Kewajiban Peserta BPJS Kesehatan. Diakses pada tanggal 21 Maret 2017, pukul 14.42 WIB http://tips-sehat-keluargabunda.blogspot.com/2014/09/hak-dan-kewajiban-peserta-bpjskesehatan.html.

Dasar hukum terbentuknya BPJS kesehatan, diakses pada tanggal 21 Maret 2017, pukul 14.20 WIB dari http://inacbg.blogspot.com/2014/02/dasar-hukumterbentuknya-bpjs-kesehatan.html.

BPJS Kesehatan, diakses pada tanggal 21 Maret 2017, pukul 14.00 WIB dari https://bpjs-kesehatan.go.id/bpjs/index.php/home. 